\title{
A ORGANIZAÇÃO DAS ESCOLAS DE TRABALHADORES RURAIS DO PARANÁ: O REGULAMENTO DE 1939
}

\author{
Vera Lucia Martiniak ${ }^{1}$
}

No estado do Paraná, o período ditatorial caracterizou-se por um crescente movimento de ampliação e difusão do ensino agrícola. A ampliação das instituições escolares foi peça essencial na Campanha de Nacionalização, principalmente na integração dos estrangeiros aos valores nacionais. Durante o governo de Manoel Ribas, foram criadas as Escolas de Trabalhadores Rurais que se constituíram instrumentos para a preparação da mão de obra para o setor agrícola.

O ensino agrícola paranaense passou a ser regulamentado pelo Decreto $\mathrm{n}^{\circ} 7.782 / 39$, de 06 de janeiro de 1939, que organizou e sistematizou o funcionamento das escolas de trabalhadores rurais.

O documento que se apresenta, aborda a organização curricular e administrativa das instituições de ensino agrícola no estado.

\section{O Regulamento de 1939 e a organização curricular}

Como forma de organização do ensino agrícola no Estado, o Governo estadual aprovou, por meio do Decreto $\mathrm{n}^{\mathbf{0}} 7.782 / 39$, de 06 de janeiro de 1939, o Regulamento das Escolas de Trabalhadores Rurais, sendo criados os cursos de Primário Agrícola e Agrícola Profissional. O curso Primário tinha duração de quatro anos, sendo, na primeira fase, semelhante ao ensino elementar dos grupos escolares do Estado. Conforme o Código de Ensino $^{2}$ de 1917, ainda em vigor na década de 1930, dispunha, em seu programa, os conteúdos e os procedimentos de ensino a serem desenvolvidos em cada uma das séries. $\mathrm{O}$ ensino ficou dividido em quatro séries, obrigatoriamente para os meninos de 7 a 14 anos e para as meninas de 7 a 12 anos de idade. O programa para o ensino primário para os alunos das escolas de trabalhadores rurais era o mesmo do Estado, mas, simultaneamente, recebiam formação prática voltada para a agricultura e a pecuária. Poderiam ser matriculados alunos com idade entre 10 e 14 anos, bem como seriam atendidos, em regime de internato, os menores abandonados e os órfãos, conforme encaminhamento do Juizado de Menores do Estado.

O Programa para as Escolas Primárias Rurais, além do citado anteriormente, compreendia as seguintes disciplinas:

$1^{\circ}$ ano - Trabalhos com instrumentos e máquinas agrícolas elementares de acordo com o físico do aluno. Serviço de lavras, destorramento e semeadeiras.

$2^{\circ}$ ano - Serviço de irrigação de plantações e de aplicação de adubos orgânicos e químicos. Multiplicação de plantas ornamentais. Escrituração agrícola elementar.

$3^{\circ}$ ano - Plantio e corte de gramados. Enxertos e podas de plantas ornamentais e de árvores frutíferas. Colheita de flores, legumes e frutos. Embalagem, conservação e acondicionamento. Multiplicação de plantas ornamentais por meio de sementes, estacas, mergulho e enxertia.

$4^{\circ}$ ano - Trabalhos práticos especializados em: laticínios, apicultura, sericultura, noções de redação e contabilidade agrícola; trabalhos em ferro, couro e madeira nas oficinas; drenagem e irrigação; avicultura; emprego de inseticidas e fungicidas; zootecnia, veterinária, as sementeiras e os viveiros, podas; campos de criação, 
conhecimento sobre raça de animais, doenças mais comuns e tratamento, serviços de culturas em fazendas de criação. (PARANÁ, 1939, art. $8^{\circ}$ ).

Já o curso Agrícola Profissional era ministrado em três anos, distribuído em oito cadeiras, e, ao término do curso, o aluno recebia o título de Capataz Rural. Para ingresso na Instituição, o candidato deveria ter entre 14 e 18 anos de idade, ter frequentado o curso primário e o último ano do Curso Primário Agrícola e ter sido encaminhado por uma autoridade competente, neste caso, o Juizado de Menores.

O Curso Agrícola Profissional compreendia as seguintes disciplinas, divididas em dois semestres:

Tabela 1 - Disciplinas do Curso Agrícola Profissional

\begin{tabular}{|c|c|c|}
\hline $1^{\circ}$ SÉRIE & $2^{\text {a }}$ SÉRIE & $3^{\text {a }}$ SÉRIE \\
\hline $\begin{array}{l}\qquad \mathbf{1}^{\mathbf{0}} \text { Semestre } \\
\text { Português; } \\
\text { Aritmética; } \\
\text { Álgebra; } \\
\text { Geometria; } \\
\text { Física Geral; } \\
\text { Química Geral; } \\
\text { Desenho Geométrico. }\end{array}$ & $\begin{array}{l}\qquad \mathbf{1}^{\mathbf{0}} \text { Semestre } \\
\text { Português; } \\
\text { Mineralogia Agrícola; } \\
\text { Mecânica Agrícola; } \\
\text { Botânica Agrícola; } \\
\text { Química Orgânica e Tecnologia; } \\
\text { Agricultura Geral; } \\
\text { Zootécnica Geral; } \\
\text { Geologia Agrícola; } \\
\text { Fitopatologia. }\end{array}$ & $\begin{array}{l}\qquad \mathbf{1}^{\mathbf{0}} \text { Semestre } \\
\text { Português; } \\
\text { Agricultura Especial; } \\
\text { Química Agrícola; } \\
\text { Zootécnica especial; } \\
\text { Alimentação dos Animais; } \\
\text { Horticultura, } \\
\text { Pomicultura, } \\
\text { Jardinicultura, } \\
\text { Silvicultura; } \\
\text { Economia Rural. }\end{array}$ \\
\hline $\begin{array}{l}\qquad \mathbf{2}^{\mathbf{0}} \text { Semestre } \\
\text { Português; } \\
\text { Aritmética (revisão); } \\
\text { Álgebra; } \\
\text { Geometria; } \\
\text { Física Agrícola - Metereologia; } \\
\text { Desenho de Ornamentos; } \\
\text { Química Orgânica. } \\
\text { Trabalhos práticos rurais de } \\
\text { oficinas e usinas }\end{array}$ & $\begin{array}{l}\qquad \mathbf{2}^{\mathbf{0}} \text { Semestre } \\
\text { Português; } \\
\text { Construções Rurais; } \\
\text { Máquinas Agrícolas; } \\
\text { Zoologia Agrícola; } \\
\text { Física e Química do solo; } \\
\text { Agricultura Geral; } \\
\text { Zootecnia Geral; } \\
\text { Geologia Agrícola. } \\
\text { Trabalhos práticos em serviços } \\
\text { rurais, de zootecnia, indústrias, } \\
\text { oficinas e laboratórios. }\end{array}$ & \begin{tabular}{l}
\multicolumn{2}{c}{$\mathbf{2}^{\mathbf{0}}$ Semestre } \\
Português; \\
Agricultura Especial; \\
Viticultura e Enologia ou outra \\
cultura que tivesse interesse à \\
região; \\
Zootecnia Especial; \\
Alimentação dos Animais; \\
Horticultura, Pomicultura e \\
Apicultura; \\
Indústria de Laticínios; \\
Contabilidade Agrícola; \\
Administração Rural. \\
Trabalhos práticos em serviços \\
rurais, de zootecnia e indústrias \\
rurais, oficinas, usinas e \\
laboratórios.
\end{tabular} \\
\hline
\end{tabular}

Fonte: Regulamento das Escolas de Trabalhadores Rurais, 1939.

O Regulamento explicitava os objetivos a que se destinavam as escolas de trabalhadores rurais, ou seja, eram internatos de ensino público destinado ao preparo de profissionais para a agricultura, de acordo com as necessidades técnico-práticas da lavoura e da pecuária.

Criadas e mantidas pelo Governo Estadual, essas escolas deveriam, de modo progressivo, manter-se economicamente por meio da produção da sua lavoura. As escolas ofereciam, também, o ensino agrícola para as mulheres, porém funcionavam em prédios 
distintos e independentes. O ensino destinado ao público feminino era acrescido de educação doméstica "[...] a fim de torná-la ótima dona de casa rural" (PARANÁ, 1939, artigo $\left.6^{\circ}\right)$.

Na organização das escolas eram oferecidos os seguintes serviços aos internos: assistência alimentar, higiênica, sanitária e educacional, oficinas para trabalhos com ferro, madeira e couro, campo de culturas, posto zootécnico e campo de criação.

Ressalta-se, ainda, que, no Regulamento das Escolas, de 1939, constata-se o ensino eminentemente prático, em que o aluno, por meio de várias disciplinas de teor prático, deveria aprender fazendo.

\section{A estrutura diretiva e administrativa das escolas de trabalhadores rurais conforme o Regulamento de 1939.}

Em se tratando das escolas de trabalhadores rurais que ofereciam atendimento em regime de internato, o quadro de pessoal era grande e variado, contando com, no mínimo, vinte e duas pessoas. De acordo com o Regulamente, nesse contingente, deveria haver profissionais, que supervisionassem os internos, garantindo alimentação, roupas limpas, assistência médica e odontológica, além de ministrarem as disciplinas específicas do ensino agrícola.

A "equipe dirigente" das escolas, neste caso o diretor e o secretário (que poderia assumir o cargo de direção quando necessário), deveria se preocupar com a manutenção do controle disciplinar, tanto dos internos quanto dos funcionários e, para tanto, era auxiliada pelo chefe da disciplina, pelos assistentes educacionais e pelo guardião, que fiscalizavam a rotina diária das escolas.

Era atribuída ao diretor da Instituição a fiscalização de todas as condutas dos internos e dos funcionários. Conforme o artigo 16, o diretor poderia propor a admissão ou a exoneração de funcionários titulados ou não, conforme conveniência moral ou material. Adiante, explicita outra atribuição de controle, "dirigir, orientar e fiscalizar as atividades agrícolas da escola, a prática da lavoura, orientando e fiscalizando o trato do rebanho e a aprendizagem dos internos".

E para garantir a disciplina e a aprendizagem dos internos, o Regulamento associou o mecanismo de controle a um sistema de trabalho que consistia na subdivisão dos alunos em grupos com, no máximo, 50 alunos, para que cada grupo fosse coordenado por um funcionário. O controle disciplinar dos internos também era auxiliado pelos assistentes educacionais, que poderiam ser professores diplomados do magistério público ou pessoas nomeadas pelo Governo, que tinham a incumbência de "vigiar todos os passos dos educandos, acompanhando-os no estudo, nas refeições e no banho, nos recreios e no trabalho, para orientá-los com conhecimento de causa" (REGULAMENTO, 1939, art. 29).

Além da "equipe dirigente", a instituição contava com profissionais que desempenhavam serviços específicos no internato. Eram funcionários que exerciam as funções de cozinheira, roupeira, lavadeira e porteiro-protocolista entre outros cargos. Esses profissionais garantiriam as condições necessárias e básicas para a manutenção dos alunos nas escolas.

Já o quadro docente constituía-se de professores de ensino primário, um professor para cada uma das cadeiras de curso agrícola profissional e um instrutor de educação física. Esses professores eram auxiliados pelos seguintes profissionais: um chefe de 
cultura, para cada grupo de 50 internos, e um assistente de pecuária escolar. Para as oficinas estavam previstos ainda: um mestre ferreiro, um mestre carpinteiro, um mestre seleiro e um técnico de indústrias rurais. Com a oferta do ensino primário e profissional, os professores do primeiro grupo "[...] não traziam a mínima ideia do necessitariam lecionar no ensino profissional" (CUNHA, 2005, p. 80). Por sua vez, os mestres de ofícios ensinavam os internos sem a necessária base teórica para a aprendizagem.

Por seu regime de internato, os alunos eram assistidos por profissionais que deveriam zelar pelas condições de saúde e alimentação, como a enfermeira e o dentista, que faziam parte do quadro funcional da escola.

Tabela 2 - Quadro de funcionários, conforme o Regulamento de 1939.

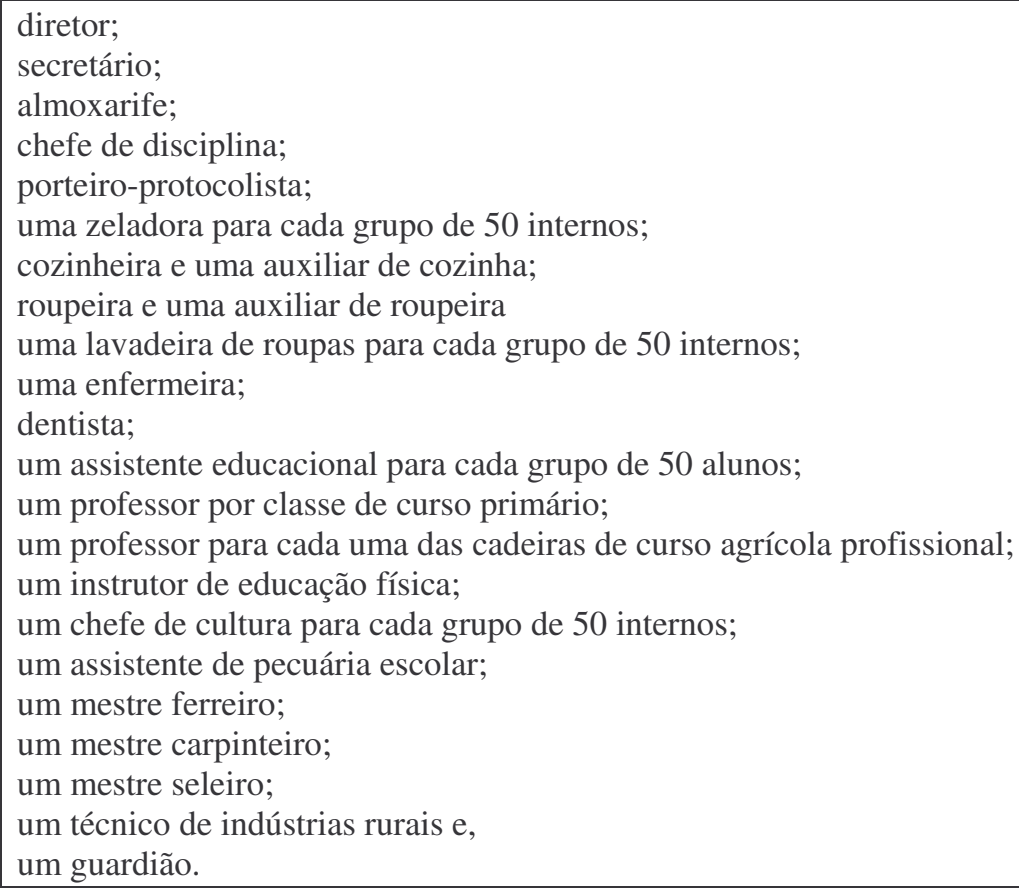

Fonte: Regulamento das Escolas de Trabalhadores Rurais, 1939.

Os artigos 37 e 38 do referido Regulamento elencam os requisitos para a admissão de alunos nas escolas. Segundo esse Regulamento, além do pagamento da matrícula e das mensalidades, isentando os alunos que fossem considerados menores abandonados ou órfãos, o candidato deveria ter entre 10 e 14 anos de idade, deveria ser normal, precisaria ser aprovado na inspeção de saúde e não poderia apresentar defeito físico que o inabilitasse para o aprendizado do ofício pretendido. Além desses requisitos, o candidato deveria, ainda, ter boa conduta e ser encaminhado pela autoridade competente, neste caso o Juizado de Menores.

Para frequentar o Curso Agrícola Profissional, o candidato deveria ter entre 14 e 18 anos de idade e ter concluído o último ano do curso primário agrícola.

Com a organização do ensino agrícola e com a aprovação do Regulamento para as Escolas de Trabalhadores Rurais, o Relatório do Interventor Manoel Ribas, enviado ao Presidente Getulio Vargas, em 1942, apresentava um tom otimista em relação ao ensino público no Estado. No Relatório, o Interventor enaltecia a preocupação com a campanha de alfabetização e a incrementação da educação integral ${ }^{3}$. Mais além, salientava que o ensino agrícola teve um desenvolvimento extraordinário, e, por isso, justificava a criação de mais duas novas escolas: uma no município de Palmeira e a outra no município de Rio Negro. 


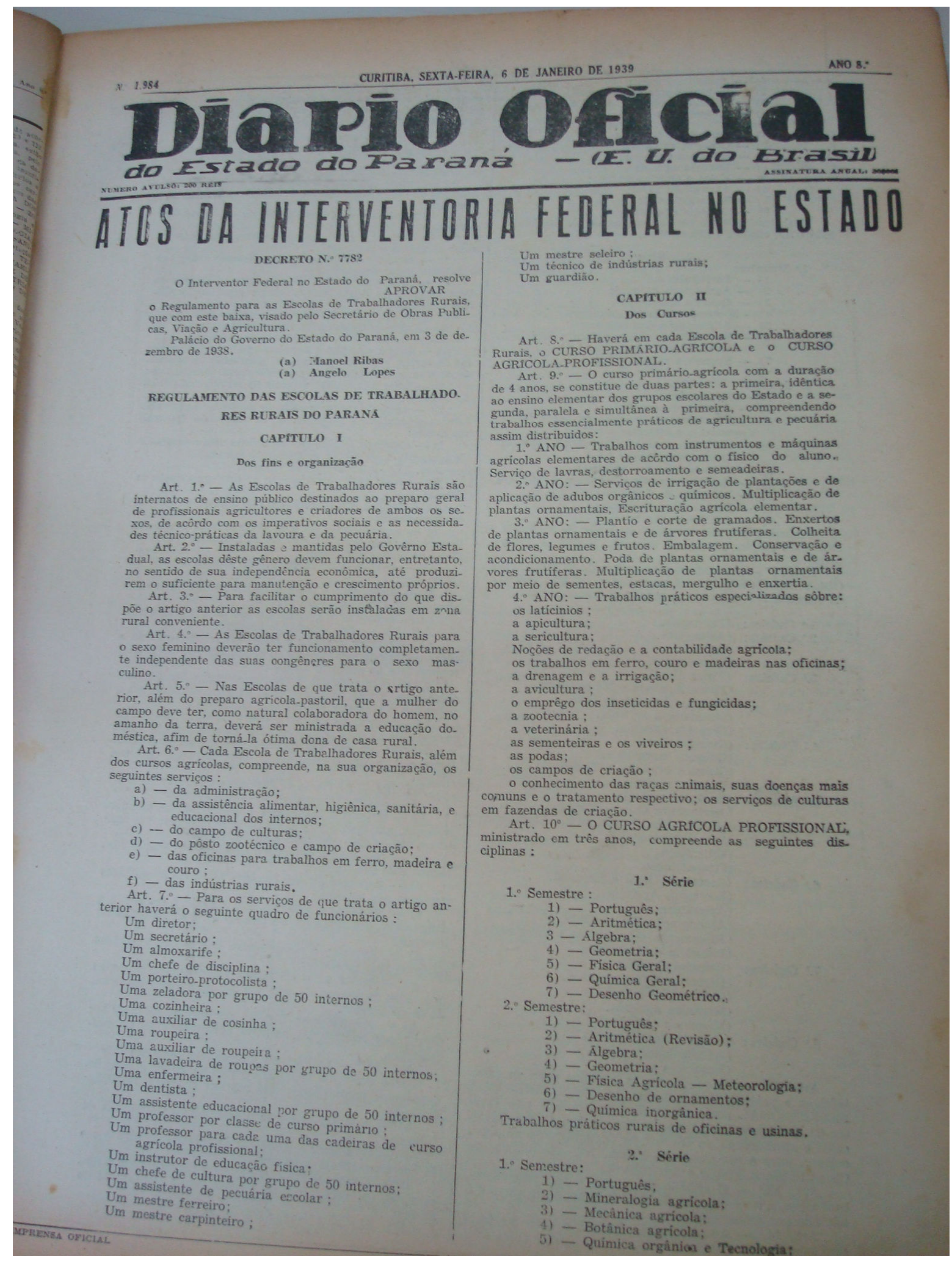




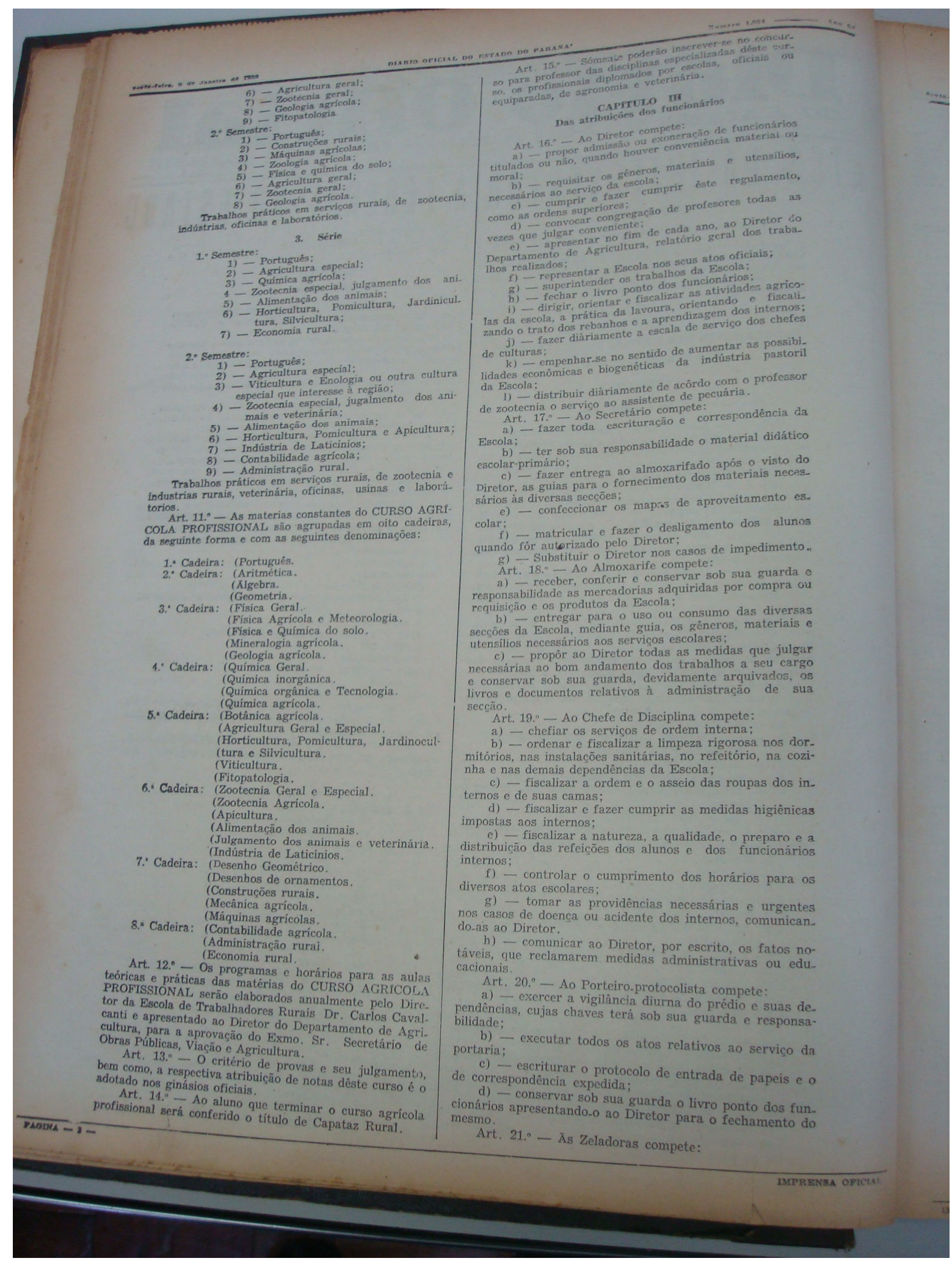




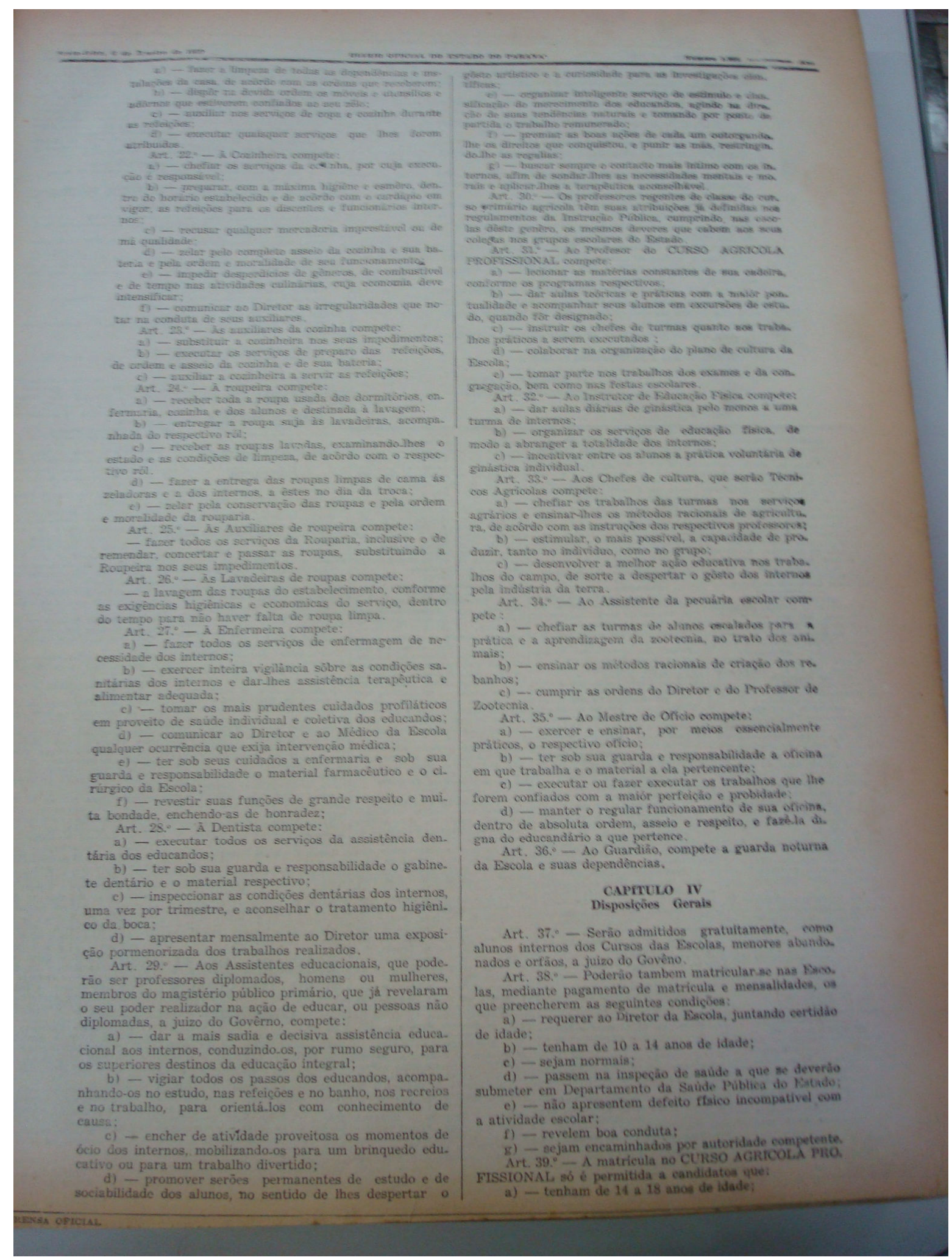




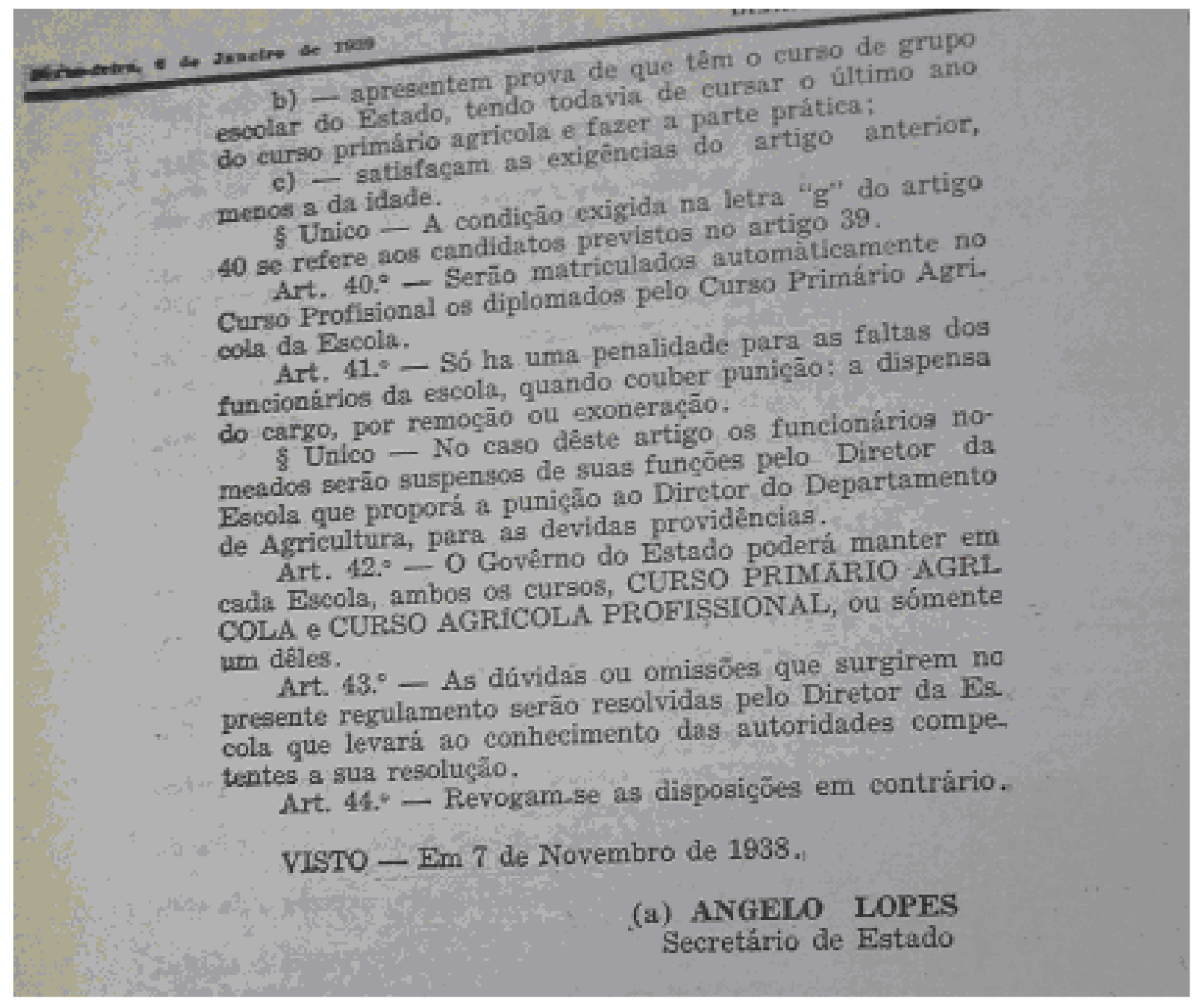

\footnotetext{
${ }^{1}$ Doutoranda em Educação, pela Universidade Estadual de Campinas, professora da Faculdade Sant'Ana e da Universidade Estadual de Ponta Grossa/PR.

${ }^{2}$ Em 1937 seria aprovado um novo Código, porém o Golpe de Estado, naquele ano, impediu sua aprovação e permaneceu em vigor o Código de Ensino de 1917.

${ }^{3}$ Entende-se por educação integral, neste período, a possibilidade de formação completa do homem.
} 